\title{
Sea level rise projections for northern Europe under RCP8.5
}

\author{
Aslak Grinsted $^{1,2, *}$, Svetlana Jevrejeva ${ }^{2,3}$, Riccardo E. M. Riva ${ }^{4}$, Dorthe Dahl-Jensen ${ }^{1}$ \\ ${ }^{1}$ Centre for Ice and Climate, Niels Bohr Institute, University of Copenhagen, 2100 Copenhagen Ø, Denmark \\ ${ }^{2}$ College of Global Change and Earth System Science, Beijing Normal University, 100875 Beijing, PR China \\ ${ }^{3}$ National Oceanographic Centre, Liverpool L3 5DA, UK \\ ${ }^{4}$ Department of Geoscience and Remote Sensing, Delft University of Technology, 2628 CN Delft, The Netherlands
}

\begin{abstract}
Sea level rise poses a significant threat to coastal communities, infrastructure, and ecosystems. Sea level rise is not uniform globally but is affected by a range of regional factors. In this study, we calculate regional projections of 21st century sea level rise in northern Europe, focusing on the British Isles, the Baltic Sea, and the North Sea. The input to the regional sea level projection is a probabilistic projection of the major components of the global sea level budget. Local sea level rise is partly compensated by vertical land movement from glacial isostatic adjustment. We explore the uncertainties beyond the likely range provided by the IPCC, including the risk and potential rate of marine ice sheet collapse. Our median 21st century relative sea level rise projection is $0.8 \mathrm{~m}$ near London and Hamburg, with a relative sea level drop of $0.1 \mathrm{~m}$ in the Bay of Bothnia (near Oulu, Finland). Considerable uncertainties remain in both the sea level budget and in the regional expression of sea level rise. The greatest uncertainties are associated with Antarctic ice loss, and uncertainties are skewed towards higher values, with the 95th percentile being characterized by an additional $0.9 \mathrm{~m}$ sea level rise above median projections.
\end{abstract}

KEY WORDS: Regional sea level $\cdot$ Coastal adaptation $\cdot$ British Isles $\cdot$ Fennoscandia $\cdot$ Relative sea level · Tail-risk

\section{INTRODUCTION}

Global warming leads to loss of land-based ice masses and thermal (steric) expansion of the world oceans (Church et al. 2013a), and is thus causing sea levels to rise. The rise in global mean sea level (GMSL) is projected to accelerate over the 21st century (Grinsted et al. 2010, Jevrejeva et al. 2010, 2012, Church et al. 2013a). However, sea level does not rise in a globally uniform manner, but has been observed to vary in complex spatial patterns (Church et al. 2013a). The projected changes in regional sea level will deviate markedly from the global mean for a variety of reasons. For example, in the Baltic region, land uplift caused by glacial isostatic adjustment (GIA) is still ongoing. This is predominantly a result

*Corresponding author: ag@glaciology.net of the viscoelastic response of the solid Earth to the disappearance of the Fennoscandian ice sheet at the end of the last glacial period. GIA is currently responsible for lowering sea level in the Bay of Bothnia at a rate of $1 \mathrm{~m}$ per century (Hill et al. 2010). The dynamic topographic sea surface response to climate change will be far from uniform. Furthermore, the wastage of land-based ice masses worldwide will cause an uneven mass redistribution across the world oceans (Mitrovica et al. 2001). A practical approach to projecting regional sea level rise is to project the individual major contributions to GMSL rise, and to weigh each contribution with its corresponding spatial fingerprint (e.g. Slangen et al. 2011).

Rising sea levels pose an increasing threat to coastal infrastructure (Brown et al. 2011), and as a

() The authors 2015. Open Access under Creative Commons by Attribution Licence. Use, distribution and reproduction are unrestricted. Authors and original publication must be credited. 
result, future projection scenarios are needed to aid local adaptation planning. There have been several national projections of regional sea level for the Netherlands (Katsman et al. 2008, 2011), Norway (Simpson et al. 2012), Finland (Johansson et al. 2014), and the British Isles (Lowe et al. 2009, Howard et al. 2014). Most of these studies focus on providing a best-guess or a high-end estimate of future relative sea level rise, which does not have any probability attached (with exception of Johansson et al. 2014). However, probabilistic projections enable adaptation planning with different levels of risk tolerance, but current models do not allow a quantification of the magnitude and risk associated with the marine ice sheet instability (Church et al. 2013a). Here, we make probabilistic projections of northern European sea level rise, including the risk and potential contribution from an Antarctic marine ice sheet collapse. Perrette et al. (2013) and Johansson et al. (2014) have also constructed probabilistic projections of regional sea level rise by combining semi-empirical and process based projections. There is, however, no consensus on the reliability of semiempirical projections (Church et al. 2013a). Kopp et al. (2014) combined the AR5 projections (Church et al. 2013a) with the results from an ice sheet expert elicitation (Bamber \& Aspinall 2013) adjusted to match the AR5 ice sheet projections. The expert elicitation has the benefit that experts can account for known structural uncertainties such as the marine ice sheet response. In this study, we also rely on this expert elicitation to capture the uncertainty in the future ice sheet response, but unlike Kopp et al. (2014), we do not adjust the elicitation results which we take to be representative of the full uncertainty within the ice sheet expert community. What is unique about our study is: (1) we include land water and shelf mass loading fingerprints; (2) the way we sample uncertainties; and (3) the special attention we give to regionally important effects.

This study is part of a special issue on the effects of extreme global warming in northern Europe, and hence, we focus on the most intense Representative Concentration Pathway (RCP8.5) considered by the Fifth Assessment Report of the Intergovernmental Panel on Climate Change (IPCC AR5; Church et al. 2013a). This scenario is consistent with a businessas-usual scenario (Riahi et al. 2011) and is thus relevant for regional adaptation planning. The central estimate for the projected global mean warming by 2100 under RCP8.5 is roughly $+5^{\circ} \mathrm{C}$ above the preindustrial period, and $+6^{\circ} \mathrm{C}$ is reached by the mid 22nd century (Rogelj et al. 2012).

\section{MATERIALS AND METHODS}

The conventional approach to project sea level rise is to simulate the individual major sea level components of the global sea level budget: ocean steric expansion $(T)$, melting/dynamics of glaciers (GIC), ice loss from the Greenland and Antarctic ice sheets (GrIS and AIS), and changes in land water storage (LW) and then sum them up (Church et al. 2013a). We write this as:

$$
\mathrm{GMSL}=\mathrm{GIC}+\mathrm{GrIS}+\mathrm{AIS}+T+\mathrm{LW}
$$

For regional sea level, each contributor to GMSL rise will have a distinct spatial 'fingerprint' (i.e. characteristic pattern). It is therefore necessary to estimate how the sea level budget evolves into the future when we aim to project regional sea level rise.

All masses, such as the ice contained in the Greenland ice sheet, gravitationally attract the oceans around them. Projected mass loss of the glaciers and ice sheets will reduce this gravitational pull, as well as cause an immediate elastic rebound of the solid Earth (Church et al. 2013a). Additionally, the mass redistribution will perturb the Earth's rotation (Milne \& Mitrovica 1998a). These effects combine and produce a new so-called static equilibrium (SE) in the sea level configuration. This equilibrium is only quasistatic as it will vary over time as mass is added or removed from the ocean. The net SE response from melting ice is that the sea level contribution will not be distributed evenly on Earth but will rather be characterised by a specific spatial fingerprint. E.g. ice loss from Greenland may result in a lowering of sea level until Ireland and Norway, primarily due to the reduced gravitational pull (Mitrovica et al. 2001; see Fig. S3 in the Supplement at www.int-res.com/articles/ suppl/c064p015_supp.pdf). The sea level fingerprints of mass redistribution applied in the present study have all been calculated by solving the sea-level equation (Farrell \& Clark 1976), following a pseudospectral approach (Mitrovica \& Peltier 1991), including the effects of migrating coastlines (Milne \& Mitrovica 1998b) and of changes in the Earth's rotation (Milne \& Mitrovica 1998a). The elastic response of the solid Earth has been computed for a radially stratified and compressible Earth based on the Preliminary Reference Earth Model (PREM) (Dziewonsky \& Anderson 1981).

Steric expansion of the oceans will be largest in the open ocean where the water column is deepest (Yin et al. 2010). This non-uniform expansion leads to a differential increase in the steric sea surface heights (SSH), which will drive a redistribution of ocean mass 
from the deep ocean interior to shallower regions (Landerer et al. 2007). Changes in ocean circulation and in the hydrological cycle induce additional changes. We combine the global average steric response $(T)$ with the dynamic sea level (DSL) response (Landerer et al. 2007, Yin et al. 2010). The mass redistribution towards shelf areas induce increased gravitational attraction as well as increased loading on the sea floor, and is thus associated with a shelf mass loading (SML) sea level fingerprint (Richter et al. 2013).

We express the relative sea level (RSL) at every location $(x)$ from the 5 major contributions to GMSL ( $T$, GIC, AIS, GrIS, and LW), the dynamic ocean response (DSL), their corresponding spatial fingerprints $\left(F_{\mathrm{SML}}, F_{\mathrm{GIC}}, F_{\mathrm{LW}}, F_{\mathrm{GrIS}}\right.$, and $\left.F_{\mathrm{AIS}}\right)$, and the glacial isostatic adjustment (GIA) as follows:

$$
\operatorname{RSL}(x)=\begin{aligned}
& F_{\mathrm{GIC}}(x) \mathrm{GIC}+F_{\mathrm{GrIS}}(x) \mathrm{GrIS}+F_{\mathrm{AIS}}(x) \mathrm{AIS}+ \\
& F_{\mathrm{SML}}(x)(T+\operatorname{DSL}(x))+F_{\mathrm{LW}}(x) \mathrm{LW}+\mathrm{GIA}(x)
\end{aligned}
$$

We express the fingerprints from terrestrial ice melt and land water as spatial multipliers to their global average contribution to sea level rise. The SML fingerprint was calculated from projected ocean bottom pressure change from NorESM1-M, but expressed as a multiplier to the local change in the ocean response following Richter et al. (2013). This is an approximation that only holds if the mass redistribution used to calculate $F_{\text {SML }}$ is consistent with $T+$ DSL.

We use a Monte Carlo procedure to draw samples from the uncertainty distributions of all terms in Eq. (2) simultaneously to obtain an uncertainty distribution for RSL. We emulate the AR5 projection uncertainties using a multivariate normal distribution with a covariance structure designed to be consistent with the AR5 likely range, combined with independent uniform distributions for LW and rapid ice sheet dynamics (see the Supplement and Jevrejeva et al. 2014a).

\subsection{Data}

As input to our sea level projection, we primarily rely on the IPCC AR5 process-based projections of the sea level budget (Church et al. 2013a). The AR5 did not provide estimates beyond the likely range (i.e. the $66 \%$ uncertainty interval), primarily because of limitations in ice sheet modelling (Church et al. 2013a,b). It was concluded that an instability of marine-based sectors of the ice sheets could lead to sea level rise beyond the projected likely range, but that this scenario was unlikely (Church et al. 2013a). To capture the uncertainty distribution beyond the likely range, we use the Bamber \& Aspinall (2013) expert elicitation for the ice sheet contribution (see the Supplement and Jevrejeva et al. 2014a). This elicitation captures the current degree of uncertainty within the community of ice-sheet experts and includes the perceived risk and potential rate from marine ice sheet instabilities. Post-AR5 studies indicate that Pine Island Glacier in Antarctica is already engaged in an unstable retreat (Favier et al. 2014, Mouginot et al. 2014, Rignot et al. 2014), a situation that is projected to extend to the neighbouring Thwaites glacier (Favier et al. 2014, Joughin et al. 2014), and even to East Antarctica (Sun et al. 2014). These new studies highlight the importance of including the risk of a collapse in the sea level projection uncertainties, and arguably, this is increasingly important for high-end scenarios.

We use the AR5 emulator to draw samples of $T$, GIC, and LW in the Monte Carlo sampling of uncertainties. Bamber \& Aspinall (2013) provide us with the joint distribution of the rate of mass loss in 2100 for Greenland and East/West Antarctica. We assume a constant acceleration to these rates from the present day rates (Shepherd et al. 2012) to calculate the cumulated mass loss over the 21st century. We model the uncertainties in GrIS and AIS by sampling the uncertainties in these 2 studies. This frameworkwhere the projections of $T$, GIC, LW are based on AR5 and projections of AIS and GrIS are based on Bamber \& Aspinall (2013) — is identical to the GMSL projection in Jevrejeva et al. (2014a), where the probability distributions for each contributor are shown.

The dynamic sea level has been modelled by the ensemble of models in the CMIP5 archive (Taylor et al. 2012), but unfortunately, the Baltic region is still poorly resolved in many models. We therefore restrict the DSL to 12 CMIP5 models that resolve the Baltic and the English Channel (ACCESS1-0, ACCESS1-3, CNRM-CM5, GFDL-ESM2G, GISS-E2-R, IPSL-CM5A-LR, MPI-ESM-LR, MPI-ESM-MR, MRICGCM3, NorESM1-ME, NorESM1-M, and inmcm4). The uncertainty implied by the ensemble spread cannot be captured by a normal distribution because there are signs of bi-modality (Fig. S1 in the Supplement). Hence, we sample among these 12 DSL fields in the Monte Carlo, rather than using the ensemble mean and standard deviation.

Here, we use previously published fingerprints computed from present day spatial patterns of terrestrial ice loss (Bamber \& Riva 2010, Radi \& Hock 2011) and projected changes from ocean dynamics (Richter 
et al. 2013). We calculate a new land water fingerprint using projected changes in land water storage (Wada et al. 2012). Fingerprint uncertainties arise primarily from uncertainties in future loading patterns, and we allow for standard uncertainties of $\sim 15$, $2,15,5$, and $5 \%$ in the Greenland, Antarctic, Glacier, Land Water, and SML fingerprints respectively. These uncertainties were gauged through comparison to alternative loading patterns (see the Supplement).

We use outputs of 2 separate regional models for the present-day GIA contribution to RSL, calibrated to Fennoscandia and the British Isles. For Fennoscandia, we use GIA contributions to RSL from the Hill et al. (2010) model, which is calibrated against observations from GPS, tide-gauges, and GRACE gravity observations while allowing for GPS reference frame uncertainties. For the British Isles, we use the GIA contribution to RSL from Bradley et al. (2011), which is primarily calibrated against paleo data of relative sea level and further constrained by GPS observations. The GPS data was a constraint on the possible range of Earth model parameters, and the Bradley et al. (2011) regional sea level results are insensitive to changes in GPS reference frame. GIA model uncertainties are hard to quantify, and arise mostly from unknown systematic errors, and there is a particularly large spread between different GIA models in northern Europe (Jevrejeva et al. 2014b). Hill et al. (2010) report standard uncertainties of generally $<4 \mathrm{~cm}$ per century. However, we observe a decimeter per century disagreement in the region where the 2 GIA models overlap (Fig. S2 in the Supplement). We therefore adopt a more conservative standard uncertainty of $10 \mathrm{~cm}$ per century for the GIA.

\section{RESULTS}

We calculate the GMSL rise as the sum of the projected contributions from glaciers, steric, ice-sheets, and land-water (Eq. 1). Fig. 1 shows the global sea level rise uncertainty distribution (Table 1, Table S2 in the Supplement at www.int-res.com/articles/ suppl/c064p015_supp.pdf; Jevrejeva et al. 2014a), which is highly skewed with a long high-end tail (skewness $=1.8$ ), stemming from the ice-sheet expert uncertainties (Bamber \& Aspinall 2013). A consequence is that the mode of the GMSL uncertainty distribution $(0.70 \mathrm{~m})$ is smaller than the median $(0.80 \mathrm{~m})$, which again is smaller than the expected value (0.91 m). Similarly, we obtain uncertainty distributions of RSL rise at every location from the Monte Carlo sampling of the uncertainties of all terms in

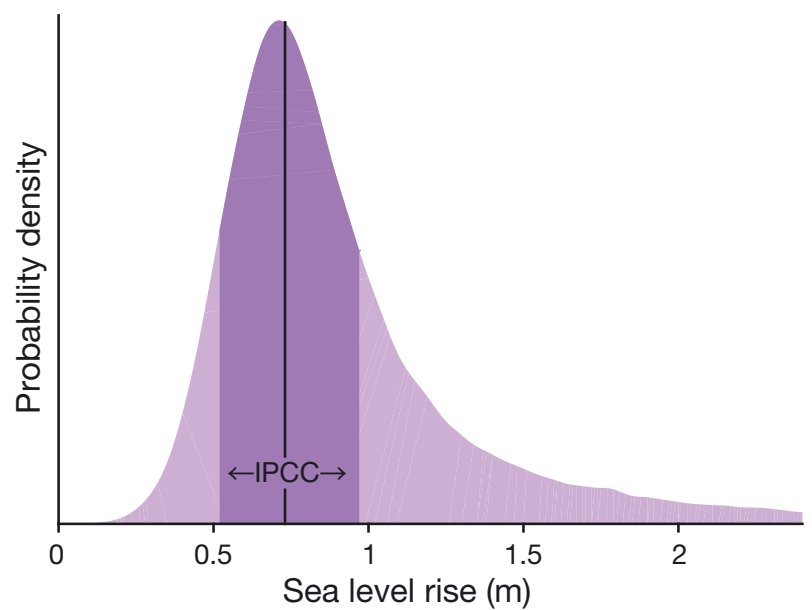

Fig. 1. Uncertainty in projected 21st century global mean sea level rise for RCP8.5. The vertical black line and darker shaded range show the median and likely range as projected in IPCC AR5 (Church et al. 2013a). The 5, 17, 50, 83, and 95th percentiles in the uncertainty distribution are listed in Table 1

Table 1. Global mean sea level rise $\left(\mathrm{cm} \mathrm{century}^{-1}\right)$ over the period 2000 to 2100 for RCP8.5 compared to other recent projections. The median projection is the best guess; the $17-83 \%$ is the likely range; 5 to $95 \%$ is the very likely range

\begin{tabular}{|lccccc|}
\hline & \multicolumn{5}{c|}{ Percentile } \\
\cline { 2 - 6 } & $5 \%$ & $17 \%$ & $50 \%$ & $83 \%$ & $95 \%$ \\
\hline AR5 & & 52 & 73 & 97 & \\
SEM & & & 113 & & 130 \\
Horton et al. (2014) $_{\text {Kopp et al. (2014) }}^{50}$ & 70 & & 120 & 150 \\
Johansson et al. (2014) & 52 & 62 & 79 & 100 & 121 \\
This study & 26 & 41 & 72 & 118 & 155 \\
a The SEM estimate for a given percentile is the median \\
of the 8 semi-empirical projections considered in AR5 \\
$\begin{array}{l}\text { adjusted for baseline intervals } \\
\text { bNot RCP8.5 but based on a combination of scenarios }\end{array}$ \\
\hline
\end{tabular}

Eq. (2). Fig. 2 shows the regional sea level projection for 6 different uncertainty percentiles, and these projections are shown in detail for select cities in Table 2, Fig. 3, and Fig. S4. The RSL rise uncertainties are also characterized by a skewed and long tailed distribution, with the 95th percentile being $0.9 \mathrm{~m}$ higher than the median sea level (Table 2). The London RSL budget is examined in detail in Table S2.

\section{DISCUSSION}

We compare the GMSL projection and uncertainties with AR5 projections, semi-empirical models, Kopp et al. (2014), and a sea level expert survey (Horton et al. 2014) in Table 1. There is a reasonable 


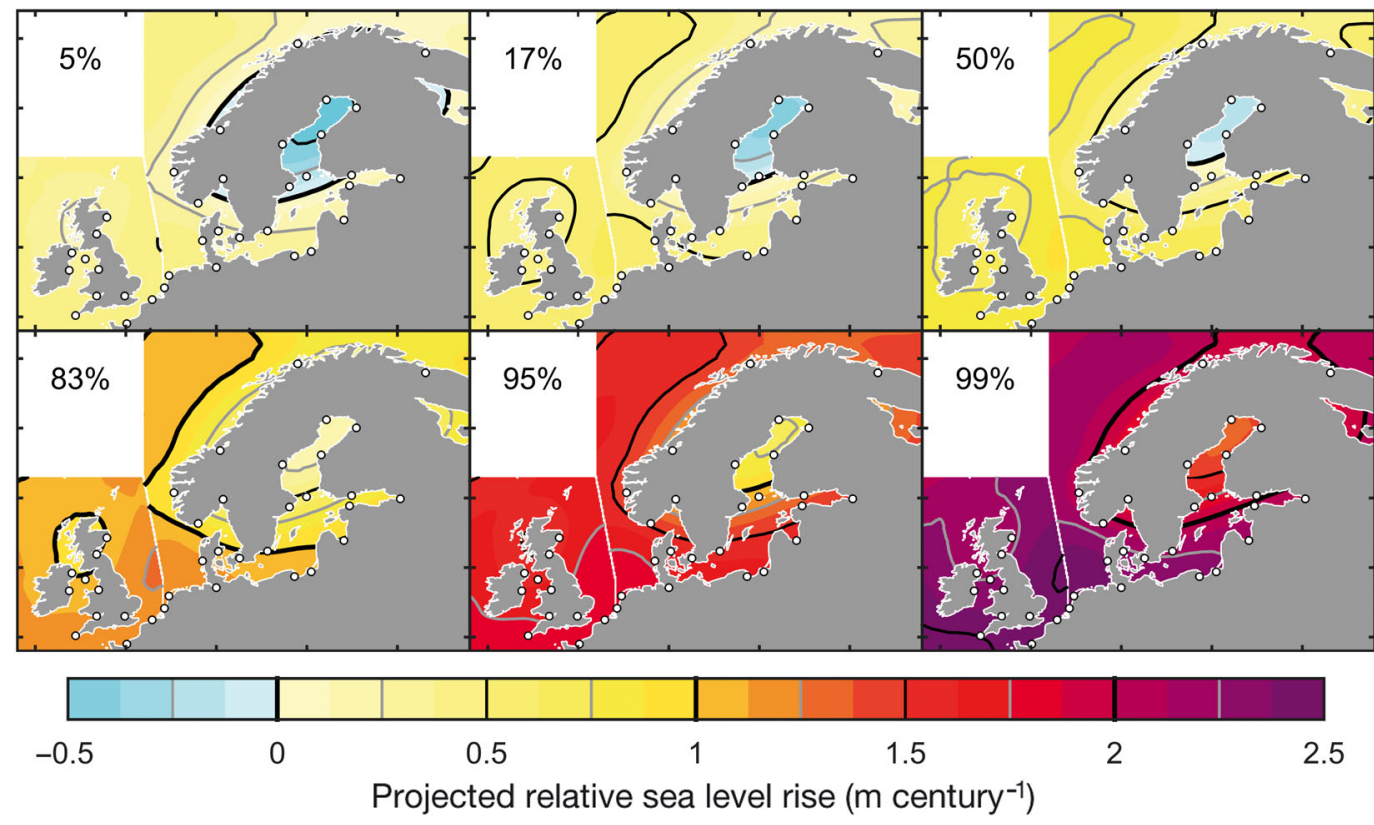

Fig. 2. Regional sea level projection for northern Europe for 6 different uncertainty percentiles (5, 17, 50, 83, 95, and 99\%). The $50 \%$ median projection can be considered the best guess. Dots show cities listed in Table 2

degree of overlap between the likely ranges, but note that the uncertainty distribution in this study is wider than the median semi-empirical ranges and median sea level expert range. However, median ranges will tend to be too narrow, even if the spread among estimates are representative of the full uncertainty, because individual estimates typically have too narrow uncertainty bars (Capen 1976). The AR5 has the tightest uncertainties and the lowest projections. This is expected as it is concluded in the AR5 that a

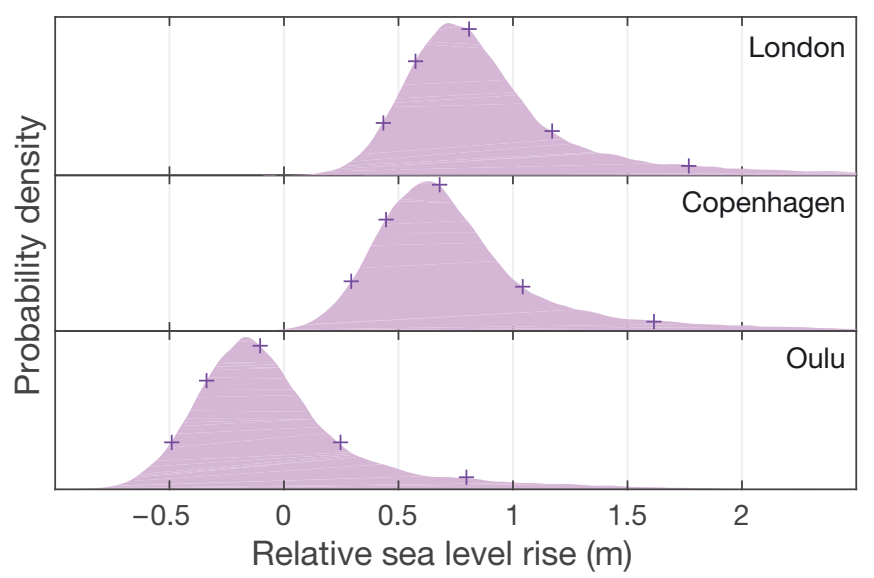

Fig. 3. Projected regional sea level rise over the 21st century and uncertainty distributions for 3 cities in northern Europe under RCP8.5. The 5, 17, 50, 83, and 95th percentiles are marked with crosses and listed in Table 2 along with results for additional cities collapse of marine-based sectors of the Antarctic ice sheet could cause GMSL to rise substantially above the projected range (Church et al. 2013a). In this sense, the AR5 projected range is conditional on no collapse. Kopp et al. (2014) provides the most direct comparison as they use a similar framework where they draw on Bamber \& Aspinall (2013) for the ice sheet contribution. They estimate a substantially smaller high-end sea level rise (1.2 vs. $1.8 \mathrm{~m}$; Table 1 ). The discrepancy is primarily due to how Kopp et al. (2014) reduce the ice sheet contribution from Bamber \& Aspinall (2013) to match the AR5 median projection, whereas we use the expert elicitation as it is. We interpret the AR5 projections to be conditional on no marine ice-sheet collapse, and because of this conditionality, the AR5 median is not equal to the median of the full uncertainty distribution. The agreement between the mode and the central AR5 projection (Fig. 1) suggests that there is no need to reconcile the ice sheet elicitation with AR5. Another source of tail discrepancy is that we allow for uncertainty covariance, which we estimate can explain a difference in the 95th percentile of $\sim 15 \mathrm{~cm}$ through sensitivity tests where we impose zero covariance between terms.

The median RSL projection in Fig. 2 is comparable to high-end projections from Spada et al. (2013) and Simpson et al. (2012), the 'semi-empirical' regional projection of Perrette et al. (2013), and the central projections from Kopp et al. (2014) and Johansson et al. (2014). The RSL projection uncertainties are 
Table 2. Regional sea level rise projection over the 21st century for cities in northern Europe (RCP8.5) for 6 uncertainty percentiles. The median projection $(50 \%)$ is the best guess. See also Fig. 3 and Fig. S3

\begin{tabular}{|lrrrrrr|}
\hline & $5 \%$ & $17 \%$ & $50 \%$ & $83 \%$ & $95 \%$ & $99 \%$ \\
\hline Dublin & 0.32 & 0.46 & 0.69 & 1.05 & 1.63 & 2.29 \\
Belfast & 0.27 & 0.41 & 0.64 & 0.99 & 1.57 & 2.22 \\
Newlyn & 0.45 & 0.59 & 0.82 & 1.2 & 1.81 & 2.49 \\
Douglas & 0.29 & 0.43 & 0.66 & 1.02 & 1.60 & 2.25 \\
Cardiff & 0.40 & 0.54 & 0.77 & 1.13 & 1.73 & 2.40 \\
Edinburgh & 0.26 & 0.41 & 0.64 & 0.99 & 1.56 & 2.20 \\
Liverpool & 0.35 & 0.49 & 0.71 & 1.07 & 1.66 & 2.31 \\
Aberdeen & 0.27 & 0.42 & 0.66 & 1.01 & 1.58 & 2.21 \\
London & 0.43 & 0.58 & 0.81 & 1.17 & 1.76 & 2.43 \\
Le Havre & 0.41 & 0.55 & 0.78 & 1.15 & 1.75 & 2.42 \\
Oostende & 0.44 & 0.59 & 0.83 & 1.20 & 1.79 & 2.47 \\
The Hague & 0.44 & 0.59 & 0.83 & 1.20 & 1.79 & 2.46 \\
Den Helder & 0.45 & 0.60 & 0.84 & 1.21 & 1.80 & 2.47 \\
Bergen & 0.13 & 0.29 & 0.52 & 0.87 & 1.42 & 2.04 \\
Kristiansand & 0.15 & 0.31 & 0.54 & 0.90 & 1.46 & 2.10 \\
Esbjerg & 0.38 & 0.53 & 0.77 & 1.14 & 1.71 & 2.37 \\
Hamburg & 0.41 & 0.56 & 0.80 & 1.16 & 1.74 & 2.39 \\
Aarhus & 0.30 & 0.45 & 0.69 & 1.05 & 1.62 & 2.27 \\
Trondheim & -0.12 & 0.04 & 0.27 & 0.61 & 1.15 & 1.76 \\
Oslo & -0.16 & -0.01 & 0.22 & 0.57 & 1.12 & 1.75 \\
Copenhagen & 0.29 & 0.44 & 0.68 & 1.05 & 1.62 & 2.27 \\
Karlskrona & 0.24 & 0.39 & 0.63 & 0.99 & 1.57 & 2.21 \\
Sundsvall & -0.47 & -0.32 & -0.09 & 0.25 & 0.81 & 1.43 \\
Stockholm & -0.13 & 0.02 & 0.25 & 0.60 & 1.17 & 1.80 \\
Gdansk & 0.34 & 0.49 & 0.73 & 1.10 & 1.67 & 2.32 \\
Tromsø & 0.04 & 0.19 & 0.43 & 0.75 & 1.30 & 1.91 \\
Mariehamn & -0.19 & -0.04 & 0.19 & 0.54 & 1.11 & 1.75 \\
Kaliningrad & 0.33 & 0.49 & 0.73 & 1.09 & 1.67 & 2.31 \\
Vaasa & -0.52 & -0.37 & -0.14 & 0.21 & 0.77 & 1.39 \\
Luleå & -0.52 & -0.37 & -0.14 & 0.21 & 0.75 & 1.37 \\
Riga & 0.26 & 0.41 & 0.65 & 1.01 & 1.58 & 2.22 \\
Tallinn & 0.10 & 0.25 & 0.48 & 0.84 & 1.40 & 2.04 \\
Helsinki & 0.01 & 0.16 & 0.39 & 0.75 & 1.31 & 1.95 \\
Oulu & -0.49 & -0.34 & -0.11 & 0.24 & 0.79 & 1.41 \\
St. Petersburg & 0.21 & 0.36 & 0.59 & 0.95 & 1.51 & 2.13 \\
Murmansk & 0.04 & 0.20 & 0.43 & 0.77 & 1.33 & 1.95 \\
\hline
\end{tabular}

shown in detail for individual cities in Fig. 3 and Table 2. We estimate a longer high-end tail than Kopp et al. (2014), with a 95th percentile of $1.6 \mathrm{~m}$ vs. $1.2 \mathrm{~m}$ at Copenhagen. This RSL discrepancy in the high-end tail is smaller than that for GMSL because uncertainty covariance between the AIS and GrIS contributions becomes unimportant locally as the fingerprint for GrIS is near zero. The median projection is considerably higher than the mid-range/central projections offered in the UKCP 2009 report (Lowe et al. 2009), in Katsman et al. (2008). The 'High++' scenario $(0.9$ to $1.9 \mathrm{~m})$ in UKCP09 was regarded as very unlikely (Lowe et al. 2009), but here, we estimate a $27 \%$ chance of local sea level in London exceeding
$93 \mathrm{~cm}$ under RCP8.5 (and a 3\% chance of exceeding $1.9 \mathrm{~m})$. Similarly, we find that there is a $26 \%$ chance of exceeding the high-end local sea level rise scenario constructed for the Netherlands by Katsman et al. (2011) under RCP8.5.

To investigate the RSL budget in detail, we focus on a single location (London), but the conclusions hold for the entire region. We find that the dominant uncertainty is the fate of Antarctica (see Table S2 in the Supplement, www.int-res.com/articles/suppl/ c064p015_supp.pdf), which explains $81 \%$ of the variance in RSL. The steric and dynamic ocean response, $F_{\mathrm{SML}}(T+\mathrm{DSL})$, accounts for $7 \%$ of the variance in RSL, and the GIA uncertainty accounts for $6 \%$. We find that uncertainty covariance between terms accounts for $3 \%$ of the variance in RSL, and thus is much less important than for GMSL, where it accounts for $29 \%$. This is primarily because fingerprinting reduces the importance of GrIS covariance.

Our framework for projecting RSL (Eq. 2) includes the most important terms, but some processes that are expected to have a minor impact have been excluded in this formulation. We exclude the inverse barometer effect (Church et al. 2013a), GIA acceleration (Spada et al. 2014), the ocean response to freshwater hosing (Hu et al. 2011, Stammer et al. 2011, Church et al. 2013a), and additional local sources of vertical land movement (e.g. Jessen 1970, Kiden et al. 2002, Hoogland et al. 2012), and we only partially allow for uncertainty covariance. The projected contribution from the inverse barometer effect is estimated to be -1 to $+2 \mathrm{~cm}$ in northern Europe (Church et al. 2013a). GIA-induced sea level acceleration will have a similarly small impact in the region. Spada et al. (2014) model a GIA-induced sea level acceleration in the Bay of Bothnia of up to $0.2 \mathrm{~mm} \mathrm{yr}^{-1}$ per century, which integrated over a century amounts to $1 \mathrm{~cm}$ of sea level rise above the constant trend. The magnitude of the dynamic ocean response to a freshwater forcing is more uncertain. Freshwater fluxes arising from a negative Greenland mass balance have been shown to perturb the North Atlantic circulation and thus induce changes in SSH (Hu et al. 2011, Stammer et al. 2011, Church et al. 2013a), but this effect is generally not included in the CMIP5 DSL fields used in this study. There are several potential sources of local vertical land movement in addition to GIA that can be significant. E.g. Hoogland et al. (2012) model subsidence rates in the Netherlands of up to $8 \mathrm{~mm} \mathrm{yr}^{-1}$ resulting from peat soil compaction and oxidation. Kiden et al. (2002) estimate tectonic subsidence in the order of $0.1 \mathrm{~mm} \mathrm{yr}^{-1}$ at the Belgian-Dutch North Sea coast. Jessen (1970) suggests escape of under- 
ground gas during prospecting as the cause of $5 \mathrm{~cm}$ subsidence around 1942 in Frederikshavn, Denmark. $\mathrm{Hu}$ et al. (2011) found that a very large hosing flux equivalent to $60 \mathrm{~cm}$ of global sea level rise resulted in an additional global average steric contribution of about $2 \mathrm{~cm}$ by the end of the 21st century, and had little detectable influence on DSL in the North East Atlantic shelf area. Stammer et al. (2011), however, found that atmospheric feedbacks increase the hosing response significantly in the North Atlantic, and could amount to decimetres per century for realistic melt water fluxes. We consider the potential for a large fresh water response to be our largest unaccounted for uncertainty, and suggest that it is investigated in future model intercomparison projects.

Uncertainty covariance between terms broadens the distribution and increases high-end sea level projections. In this study, we allow for covariance between GIC and $T$ and between AIS and GrIS and assume that uncertainties in DSL, GIA, LW, and the fingerprints are independent. In other words, we do not allow for uncertainty covariance between $T$ and AIS, as would be expected if ocean warming were a key driver of marine ice sheet response. As a sensitivity test, we impose maximum covariance between all 5 terms in the GMSL budget (by sorting the Monte Carlo sample) and find that this increases the 95th percentile for both GMSL and London RSL by $0.3 \mathrm{~m}$.

The expert elicitation of ice loss from Bamber \& Aspinall (2013) is independent of specific RCP scenarios, but rather is based on the individual experts assessment of future climate change. The central estimate of expected warming corresponded to a $6.4^{\circ} \mathrm{C}$ warming at the North Pole and a $3.8^{\circ} \mathrm{C}$ warming at the South Pole above pre-industrial values (with very likely ranges of $1.2^{\circ}$ to $13.1^{\circ} \mathrm{C}$ and $0.6^{\circ}$ to $7.2^{\circ} \mathrm{C}$ respectively). This is substantially less than the North Polar warming of $14^{\circ} \mathrm{C}$ for RCP8.5 projected in the CMIP5 ensemble (and $6^{\circ} \mathrm{C}$ for the South Polar warming). Thus, the expert assessment corresponds to a less intense scenario than RCP8.5, and yet allows for a substantially faster ice loss than considered in AR5.

Our probabilistic RSL projections highlight how mid-range or best-guess sea level scenarios are illdefined, and thus problematic to use in adaptation planning. Mid-range scenarios could be taken to represent the mode in the uncertainty distribution, but it could also correspond to the median or mean of the distribution. However, the mode, the median, and the mean all differ because of the asymmetric uncertainties. For example, for London, we find that the expected value of sea level rise is $18 \mathrm{~cm}$ greater than the mode.

\section{CONCLUSION}

We present a framework for projecting 21st century RSL rise including its uncertainty and apply it to northern Europe under RCP8.5. To capture the risk and potential rate of a collapse of marine-based sectors of Antarctica, we combine AR5 projections with the results from an ice-sheet expert elicitation. The probabilistic RSL projections presented here are an important step forward over mid-range and high-end sea level scenarios because they enable users to select protection levels in accordance with their risk tolerance in local adaptation planning. Our median 21 st century RSL rise projection is $80 \mathrm{~cm}$ near London and Hamburg, and a RSL drop of $10 \mathrm{~cm}$ is projected for the Bay of Bothnia (near Oulu, Finland). The uncertainties are skewed toward higher values, with the 95th percentile being characterized by $0.9 \mathrm{~m}$ additional local sea level rise over the median estimates. Consequently, the expected value of RSL is $0.1 \mathrm{~m}$ greater than the median estimate.

The dominant uncertainty in North European sea level rise is associated with the fate of Antarctica, followed by steric and GIA uncertainties. We show that it is important to consider uncertainty covariance, as it can increase the tail-risk of extreme sea level rise. The long-tailed uncertainty implies that there is a considerable risk that relative sea level rise will exceed recent high-end scenarios (Katsman et al. 2011, Simpson et al. 2012, Spada et al. 2013).

Finally, sea level rise will continue for centuries beyond 2100, and sea level rise over the 22nd century is projected to exceed that of the 21st century (Jevrejeva et al. 2012). This long-term aspect should be considered in adaptation plans.

Acknowledgements. The research was partly funded by NSFC No. 41076125, the Danish Strategic Research Council through its support of Centre for Regional Change in the Earth System (CRES; www.cres-centre.dk) under contract no DSF-EnMi 09-066868, ERC Advanced Grant no. 246815 (WATERundertheICE), and an Inge Lehmann travel grant. S.J. has received funding from the European Union's Seventh Programme for Research, Technological Development and Demonstration under Grant Agreement No: FP7ENV-2013-Two-Stage-603396-RISES-AM. R.E.M.R. acknowledges funding from The Netherlands Organisation for Scientific Research (NWO) through VIDI Grant no 864.12.012. We are grateful to J. Gregory, E. Hill, S. Bradley, W. Aspinall, K. Richter, and Y. Wada for data sharing. We acknowledge the World Climate Research Programme's Working Group on Coupled Modelling, which is responsible for CMIP, and we thank the climate modeling groups (listed in Fig. S1 of this paper) for producing and making available their model output. For CMIP, the USA Department of Energy's Program for Climate Model Diagnosis and Intercomparison provides 
coordinating support and led development of software infrastructure in partnership with the Global Organization for Earth System Science Portals.

\section{LITERATURE CITED}

Bamber JL, Aspinall WP (2013) An expert judgement assessment of future sea level rise from the ice sheets. Nat Clim Change 3:424-427

Bamber J, Riva R (2010) The sea level fingerprint of recent ice mass fluxes. The Cryosphere 4:621-627

> Bradley S, Milne G, Shennan I, Edwards RJ (2011) An improved glacial isostatic adjustment model for the British Isles. J Quaternary Sci 26:541-552

Brown S, Nicholls RJ, Vafeidis A, Hinkel J, Watkiss P (2011) The impacts and economic costs of sea-level rise in Europe and the costs and benefits of adaptation. Summary of results from the EC RTD ClimateCost Project. In: Watkiss P (ed) The ClimateCost Project. Final report. Vol 1: Europe. Stockholm Environment Institute, Stockholm

Capen EC (1976) The difficulty of assessing uncertainty. J Pet Technol 28:843-850

Church JA, Clark PU, Cazenave A, Gregory JM and others (2013a) Sea level change. In: Stocker TF, Qin D, Plattner GK, Tignor $M$ and others (eds) Climate change 2013: the physical science basis. Contribution of Working Group I to the Fifth Assessment Report of the Intergovernmental Panel on Climate Change. Cambridge University Press, Cambridge

Church JA, Clark PU, Cazenave A, Gregory JM and others (2013b) Sea-level rise by 2100. Science 342:1445

> Dziewonski AM, Anderson DL (1981) Preliminary reference Earth model. Phys Earth Planet Inter 25:297-356

Farrell WE, Clark JT (1976) On postglacial sea level. Geophys J R Astron Soc 46:647-667

Favier L, Durand G, Cornford SL, Gudmundsson GH, Gagliardini O, Gillet-Chaulet F, Le Brocq AM (2014) Retreat of Pine Island Glacier controlled by marine ice-sheet instability. Nat Clim Change 4:117-121

Grinsted A, Moore J, Jevrejeva S (2010) Reconstructing sea level from paleo and projected temperatures 200 to 2100AD. Clim Dyn 34:461-472

> Hill EM, Davis JL, Tamisiea ME, Lidberg M (2010) Combination of geodetic observations and models for glacial isostatic adjustment fields in Fennoscandia. J Geophys Res 115:B07403, doi:10.1029/2009JB006967

- Hoogland T, Van Den Akker JJH, Brus DJ (2012) Modeling the subsidence of peat soils in the Dutch coastal area. Geoderma 171-172:92-97

Horton BP, Rahmstorf S, Engelhart SE, Kemp AC (2014) Expert assessment of sea-level rise by AD 2100 and AD 2300. Quat Sci Rev 84:1-6

> Howard T, Pardaens AK, Bamber JL, Ridley J and others (2014) Sources of 21st century regional sea-level rise along the coast of northwest Europe. Ocean Sci 10:473-483

$>$ Hu A, Meehl GA, Han W, Yin J (2011) Effect of the potential melting of the Greenland Ice Sheet on the meridional overturning circulation and global climate in the future. Deep-Sea Res II 58:1914-1926

Jessen A (1970) Jordsætningen i Frederikshavn 1942. Geodæetisk Instituts Meddelelser 46, Copenhagen

> Jevrejeva S, Moore J, Grinsted A (2010) How will sea level respond to changes in natural and anthropogenic forcings by 2100? Geophys Res Lett 37:L07703, doi: 10.1029/2010GL042947
Jevrejeva S, Moore JC, Grinsted A (2012) Sea level projections to AD2500 with a new generation of climate change scenarios. Global Planet Change 80-81:14-20

> Jevrejeva, Grinsted A, Moore JC (2014a) Upper limit for sea level projections by 2100. Environ Res Lett 9:104008

Jevrejeva S, Moore JC, Grinsted A, Matthews AP, Spada G (2014b) Trends and acceleration in global and regional sea levels since 1807. Global Planet Change 113:11-22

> Johansson MM, Pellikka H, Kahma KK, Ruosteenoja K (2014) Global sea level rise scenarios adapted to the Finnish coast. J Mar Syst 129:35-46

> Joughin I, Smith BE, Medley B (2014) Marine ice sheet collapse potentially underway for the Thwaites Glacier Basin, West Antarctica. Science 344:735-738

Katsman CA, Hazeleger W, Drijfhout SS, van Oldenborgh GJ, Burgers G (2008) Climate scenarios of sea level rise for the northeast Atlantic Ocean: a study including the effects of ocean dynamics and gravity changes induced by ice melt. Clim Change 91:351-374

> Katsman CA, Sterl A, Beersma JJ, van den Brink HW and others (2011) Exploring high-end scenarios for local sea level rise to develop flood protection strategies for a low-lying delta - the Netherlands as an example. Clim Change 109:617-645

Kiden P, Denys L, Johnston P (2002) Late Quaternary sealevel change and isostatic and tectonic land movements along the Belgian-Dutch North Sea coast: geological data and model results. J Quaternary Sci 17:535-546

Kopp RE, Horton RM, Little CM, Mitrovica JX and others (2014) Probabilistic 21st and 22nd century sea-level projections at a global network of tide-gauge sites. Earth's Future 2:383-406

> Landerer FW, Jungclaus JH, Marotzke J (2007) Regional dynamic and steric sea level change in response to the IPCC-A1B scenario. J Phys Oceanogr 37:296-312

Lowe JA, Howard T, Pardaens A, Tinker J and others (2009) UK Climate Projections science report: marine and coastal projections. Met Office Hadley Centre, Exeter

Milne GA, Mitrovica JX (1998a) Postglacial sea-level change on a rotating Earth. Geophys J Int 133:1-19

Milne GA, Mitrovica JX (1998b) The influence of timedependent ocean-continent geometry on predictions of post-glacial sea level change in Australia and New Zealand. Geophys Res Lett 25:793-796

> Mitrovica JX, Peltier WR (1991) On post-glacial geoid subsidence over the equatorial oceans. J Geophys Res 96: 20053-20071

> Mitrovica JX, Tamisiea ME, Davis JL, Milne GA (2001) Recent mass balance of polar ice sheets inferred from patterns of global sea-level change. Nature 409:1026-1029

> Mouginot J, Rignot E, Scheuchl B (2014) Sustained increase in ice discharge from the Amundsen Sea Embayment, West Antarctica, from 1973 to 2013. Geophys Res Lett 41: 1576-1584

> Perrette M, Landerer F, Riva R, Frieler K, Meinshausen M (2013) A scaling approach to project regional sea level rise and its uncertainties. Earth System Dynamics 4:11-29

Radić V, Hock R (2011) Regionally differentiated contribution of mountain glaciers and ice caps to future sea-level rise. Nat Geosci 4:91-94

> Riahi K, Rao S, Krey V, Cho C and others (2011) RCP 8.5-a scenario of comparatively high greenhouse gas emissions. Clim Change 109:33-57

> Richter K, Riva REM, Drange H (2013) Impact of self-attraction and loading effects induced by shelf mass loading on 
projected regional sea level rise. Geophys Res Lett 40: 1144-1148

Rignot M, Morlighem S, Morlighem M, Seroussi H, Scheuchl B (2014) Widespread, rapid grounding line retreat of Pine Island, Thwaites, Smith and Kohler glaciers, West Antarctica from 1992 to 2011. Geophys Res Lett 41:3502-3509

Rogelj J, Meinshausen M, Knutti R (2012) Global warming under old and new scenarios using IPCC climate sensitivity range estimates. Nat Clim Change 2:248-253

Shepherd A, Ivins ER, Geruo A, Barletta VR and others (2012) A reconciled estimate of ice-sheet mass balance. Science 338:1183-1189

Simpson M, Breili K, Kierulf HP, Lysaker D, Ouassou M, Haug E (2012) Estimates of future sea-level changes for Norway. Technical Report of the Norwegian Mapping Authority

Slangen ABA, Katsman CA, van de Wal RSW, Vermeersen LLA, Riva REM (2011) Towards regional projections of twenty-first century sea-level change based on IPCC SRES scenarios. Clim Dyn 38:1191-1209

Spada G, Bamber JL, Hurkmans RTWL (2013) The gravita-

Submitted: May 19, 2014; Accepted: May 3, 2015 tionally consistent sea-level fingerprint of future terrestrial ice loss. Geophys Res Lett 40:482-486

Spada G, Olivieri M, Galassi G (2014) Anomalous secular sea-level acceleration in the Baltic Sea caused by isostatic adjustment. Ann Geophys 57:S0432

Stammer D, Agarwal N, Herrmann P, Köhl A, Mechoso CR (2011) Response of a coupled ocean-atmosphere model to Greenland ice melting. Surv Geophys 32:621-642

> Sun S, Cornford SL, Liu Y, Moore JC (2014) Dynamic response of Antarctic ice shelves to bedrock uncertainty. The Cryosphere Discuss 8:479-508

- Taylor K, Stouffer RJ, Meehl GA (2012) An overview of CMIP5 and the experiment design. Bull Am Meteorol Soc 93:485-498

- Wada Y, van Beek LPH, Sperna Weiland FC, Chao BF, Wu $\mathrm{YH}$, Bierkens MFP (2012) Past and future contribution of global groundwater depletion to sea-level rise. Geophys Res Lett 39:L09402, doi:10.1029/2012GL051230

Yin J, Griffies SM, Stouffer RJ (2010) Spatial variability of sea-level rise in 21st century projections. J Clim 23: 4585-4607

Proofs received from author(s): May 28, 2015 